Research Article

\title{
Dynamic Behavior of a Suspended Steel Space Frame-Glass Composite Floor
}

\author{
Zhihao Wang ${ }^{D}$, Xin Qi, Youkun Huang, Buqiao Fan, and Xiaoke Li \\ School of Civil and Communication Engineering, North China University of Water Resources and Electric Power, \\ Zhengzhou, China \\ Correspondence should be addressed to Zhihao Wang; wangzhihao@ncwu.edu.cn
}

Received 26 June 2021; Revised 21 September 2021; Accepted 4 October 2021; Published 29 October 2021

Academic Editor: Agathoklis Giaralis

Copyright ( 92021 Zhihao Wang et al. This is an open access article distributed under the Creative Commons Attribution License, which permits unrestricted use, distribution, and reproduction in any medium, provided the original work is properly cited.

This study investigates the dynamic performance of a large-span suspended steel space frame-glass composite floor (SSSF-GCF). Both the ambient vibration and the human-induced vibration of the floor were experimentally measured to identify vertical dynamic characteristics and evaluate vibration serviceability of the floor. Although vertical dynamic characteristics of the floor based on the global simplified finite element (FE) model of the structure agree well with those identified via experimental modal analysis, the global simplified FE model significantly underestimates vertical vibration amplitudes of the floor due to the coupled effect between two layers. Accordingly, an equivalent local FE model of the floor system was proposed and updated via adjusting the vertical stiffness of the interstory hanging pillars. It is shown that the equivalent local FE model can well predict both the dynamic characteristics and human-induced vibration response of the floor. Finally, the effect of the damping ratio on the acceleration response of the floor was numerically demonstrated with the verified local FE model.

\section{Introduction}

Advancements in construction materials and techniques have supported the potential for various large-span composite floors applied in building structures, such as the steeltimber composite floor $[1,2]$, steel-concrete composite floor [3-5], steel-deck composite floor [6, 7], cold-formed steel composite floor $[8,9]$, steel space frame-concrete slab composite floor [10], and other kinds of hybrid composite floors [11-14]. Currently, these composite floors have been widely used in gymnasiums [15], offices [16], and airport lounges [17], which may be prone to human-induced vibrations due to their low natural frequencies and low damping ratios [18-20]. Obviously, a sophisticated finite element (FE) model of the floor and accurate human-induced load simulation (i.e., walking, jumping, crowd activity, etc.) are critical for vibration serviceability assessment of the floor.

The use of composite structure is a common way of approaching large-span floor structures, such as concrete composite floor with steel space grids [10] and supported beam-concrete composite floor with innovative cables [20]. With the promotion of the glass manufacturing industry, the sustainability and reusability of the glass have also been improved [21, 22]. The adoption of the steel-glass composite floors has become popular in large-span visited buildings, such as the Grand Canyon Skywalk [23] and Zhangjiajie Glass Bridge [24]. Since the steel-glass composite floor is lighter and slenderer than traditional concrete floors [25-27], the structure applied with the steel-glass composite floors is more vulnerable to human-induced activities. However, in contrast to extensive dynamic research on other kinds of composite floors, little attention has been paid to the dynamic performance of the steel-glass composite floor in previous research.

In the modeling phase, a reliable finite element (FE) model is essential for vibration serviceability assessment. For instance, the Bayesian model in multilayer structure can solve the problem that the "amount" of the measured information is smaller than the "amount" of required information for identifying the uncertain parameters [28]. Besides, Robertson et al. [29] showed that minor changes in the global model have a 
non-negligible margin on the performance through investigating a suspended solid-timber floor in ANSYS. Costa-Neves et al. [7] proposed a multistory global FE model with 8 parts, which presented the coupled phenomenon between different stories. Guo et al. analyzed a half-scale five-story building by the dynamic stiffness matrix method for promoting computational efficiency and predicting vibration response with satisfactory accuracy [30]. Ye et al. subdivided the whole system into three local domains to analyze the interaction between the plate and the multilayered elastic foundation [31]. These results indicated that the FE model needs to update constantly, for example, Bai and Ren updated a 3-D model via ambient test results [32]. Zhu et al. [33] proposed the weak constraint effect of glass curtain walls. However, the interstory relationship within a suspended cantilever structure differs from traditional structures. It should be noted that the improper FE simulation of connections adopted for suspended structures may cause inaccurate predicted vibration response [34].

This study aims to investigate the dynamic behavior of a large-span suspended steel space frame-glass composite floor (SSSF-GCF), which was applied to the visiting floor of the Mingtang Exhibition Hall in Luoyang, China. First, the outline of the building structure is introduced in Section 2, and a global simplified FE model of the structure is established in Section 3. Subsequently, the measured dynamic characteristics and human-induced vibration response of the SSSF-GCF through field vibration test are compared with those predicted by the global FE model of the structure in Section 4. A methodology for the equivalent local FE model of the floor is proposed for accurate human-induced response analysis in Section 5. Moreover, further discussions are carried out in Section 6. Finally, the main findings of this research are highlighted in Section 7.

\section{Outline of the Building Structure}

This paper focuses on the dynamic behavior of an SSSF-GCF in the Luoyang National Heritage Park, China. The steel frameglass composite floor (shown in Figure 1(a)) was designed as a suspended cantilever construction, minimizing the impact of the structure on the heritage. The Mingtang Exhibition Hall is mainly composed of two floors, and each floor looks like a symmetrical regular octagon in plane (shown in Figures 1(b) and $1(\mathrm{c})$. The upper layer is a steel truss structure, and an open octagonal hole of $4.059 \mathrm{~m}$ (side length) is in the center of the lower layer. The lower layer as a site-visiting floor $\left(470 \mathrm{~m}^{2}\right)$ has a large span of $50.9 \mathrm{~m}$. The main structure of the Mingtang Hall is supported by eight inclined square frame columns whose height and thickness are $800 \mathrm{~mm}$ and $25 \mathrm{~mm}$, respectively. The steel space frame-glass composite floor connects to the steel truss of the upper layer by twenty-four hanging pillars whose pipe section is $300 \mathrm{~mm} \times 16 \mathrm{~mm}$ (external diameter $\times$ thickness). The whole structural steel components are made of Q345. The main vibration research area consists of the steel frame and glass slabs, forming a steel space frame-glass composite floor. A steel $\mathrm{H}$ section beam is utilized in the steel space frame. In the steel space frame, a steel $\mathrm{H}$ section beam is utilized whose height, breadth, web thickness, and flange width are $150 \mathrm{~mm}, 300 \mathrm{~mm}, 6.5 \mathrm{~mm}$, and $9 \mathrm{~mm}$, respectively. Upon the steel space frame, the glass slab is composed of the traditional toughened glass with a cross section thickness of $12 \mathrm{~mm}$, which linearly supports along the steel space frame. The gaps between plates and the frame are filled with rubber connections. The outer part of the steel space frame-glass composite floor consists of a $100 \mathrm{~mm}$ thick precast reinforced concrete slab and a $95 \mathrm{~mm}$ thick decorative surface. The steel space frame and glass composite floor are connected to the reinforced concrete slab by welding. The reinforced concrete slab is auxiliary supported by sixteen inclined bras. The inclined bars adopt a square section steel beam with a height of $400 \mathrm{~mm}$ and a thickness of $20 \mathrm{~mm}$, respectively. All columns including hanging pillars are connected with other structural parts by bolt-welding joints.

\section{Finite Element Modeling of the Structure}

3.1. Global Simplified FE Model. Figure 2 shows the global simplified FE model of the structure, which was established via MIDAS GEN software (version 7.1.2). The floor was modeled using the plate element of which the rotational degrees of freedom were restrained. Since the thickness of the glass floor is only $12 \mathrm{~mm}$, the influence on the vertical stiffness of the structure can be ignored. Therefore, the geometrical and mechanical properties are equivalent to the loads on the nodes of the steel frame in the finite element model. Some components were modeled using the 6 DOF beam element, such as the inclined frame columns, the inclined support bars, the steel space frame, and the hanging pillars. Edge restraints and constraints were imposed, i.e., the six freedom degrees of the bottom nodes of the inclined frame column were constrained. Considering the behavior of the structural connections presented in the investigated structural model, all connections of the frame-to-hanging pillar and truss-to-hanging pillar were set as rigid joints. As a suspended steel space frame-glass composite floor, the hanging pillars are the main connection components, which should be paid more attention to.

3.2. Dynamic Characteristic Analysis Results. Through the global simplified FE model, the first three vertical frequencies of the building are $6.00 \mathrm{~Hz}, 12.46 \mathrm{~Hz}$, and $14.23 \mathrm{~Hz}$, respectively, and the mode shapes are also given in Figure 3. It is observed that a coupled phenomenon between two different layers occurs, which may be caused by the strong connection through the hanging pillars. Because of the human walking vibration $(1.8 \mathrm{~Hz}-2.4 \mathrm{~Hz})$, only the first vertical frequency $(6.00 \mathrm{~Hz})$ may cause the third harmonic effect, which is prone to vibration serviceability problems. In addition, the best viewing area corresponding to the most sensitive vibration area in the first vertical mode shape is point 1 in Figure 3(b). Accordingly, more attention should be paid to the first vertical vibration mode of the floor.

\section{Field Vibration Tests of the Floor}

4.1. Experimental Program. According to the literature $[15,35,36,37]$, the schematic diagram of human-structure interaction is presented in Figure 4, and the effect of the 


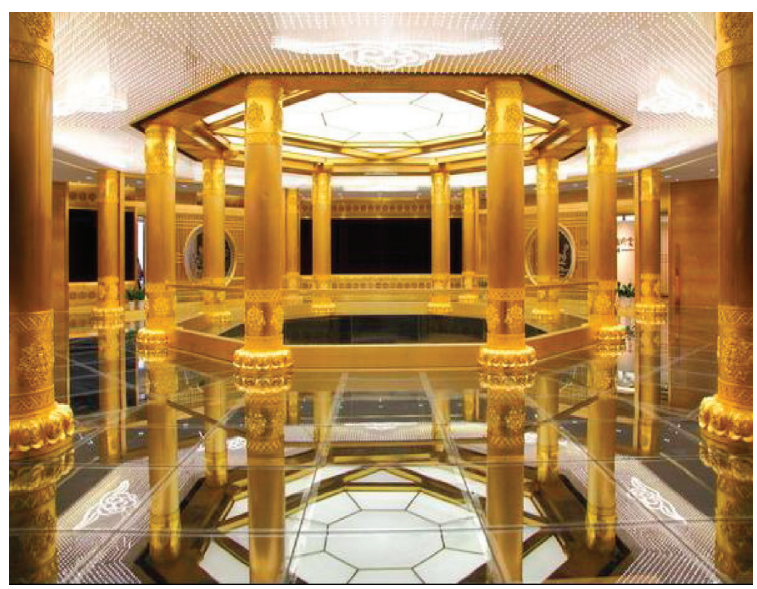

(a)

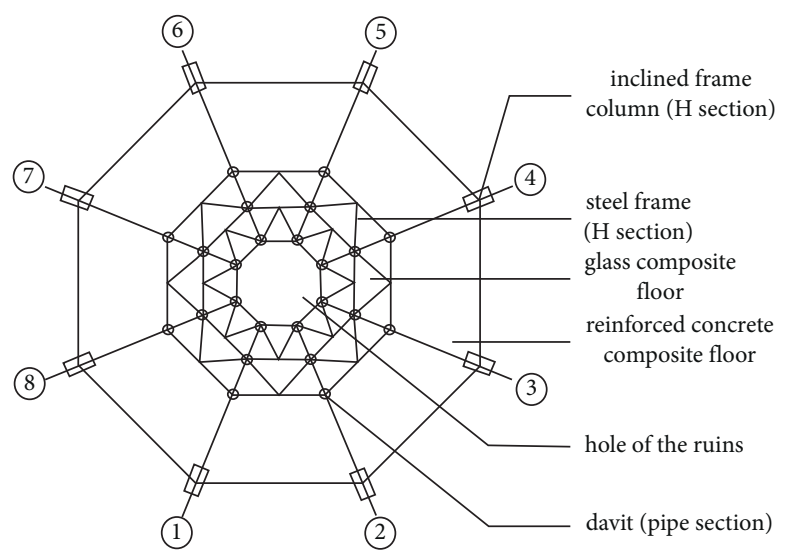

(b)

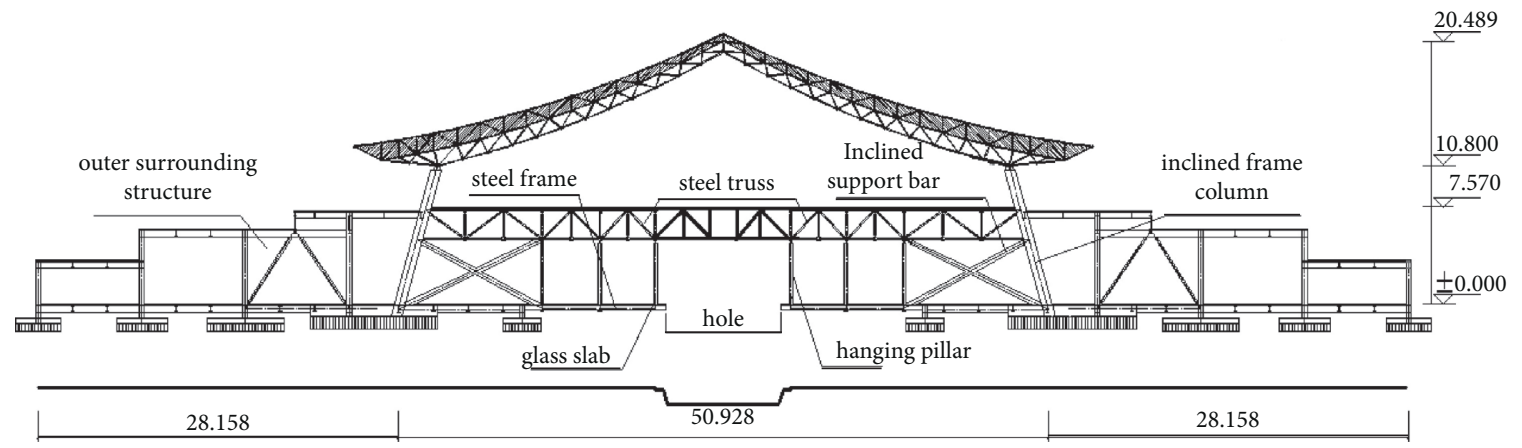

(c)

FIgURE 1: Diagram of main structure of the Mingtang Hall. (a) The steel space frame-glass composite floor. (b) Diagram of the lower layer in plan view. (c) Profile of main structure of the Mingtang Hall (m).

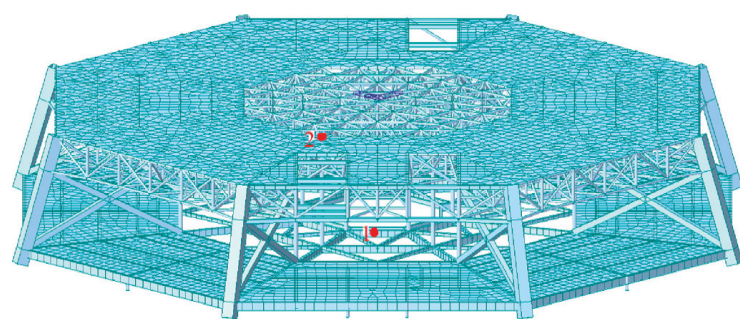

FIGURE 2: Global simplified FE model of the structure.

human-structure interaction (HSI) system is relative to the mass ratio between human and structure. Figure 4 presents the schematic diagram of human-structure interaction, and the effect of the human-structure interaction (HSI) system is relative to the mass ratio between human and structure. The larger the mass ratio, the more significant the HSI. The effect can be negligible when the ratio is quite small. Considering that the SSSF-GCF has a relatively small structural mass with respect to the pedestrians, the HSI phenomena should be properly investigated. Dynamic characteristic tests under ambient excitation were conducted to obtain the natural vibration characteristics of the structure. Human-induced vibration is sensitive to walking conditions [21]. According to the mode shape of the first mode and the test environment, vibration serviceability tests under various walking conditions were conducted. The specific descriptions of these tests are introduced in Table 1 and Figure 5.

The structural plane is completely symmetrical in accordance with the below principle of measuring point layout. Hence, symmetrical points can well perform the dynamic characteristics. The measuring points were taken at intersection nodes of the axes (1), (2), (5), and (6) and the hanging pillars. The main frame nodes between axis (1) and axis (2) were also arranged as measuring points. Measuring points were named from 1 to 15 and are plotted in Figure 6.

\subsection{Dynamic Characteristic Results}

4.2.1. Natural Frequencies. This paper pays more attention to the vertical vibration of the floor. Therefore, only vertical velocity responses were recorded for each case. The natural frequencies of the floor were directly obtained via fast Fourier transform (FFT). Figure 7 illustrates the amplitudefrequency curves of several measuring points. The measured first vertical frequencies and damping ratios are given in Table 2. The values for the structural dynamic properties are calculated from the single test data, with the natural frequency being the average value of the individual measurement points. The damping ratios were identified from the most unfavorable positions of the glass floors (measurement point 15). The predicted first vertical frequency with the 


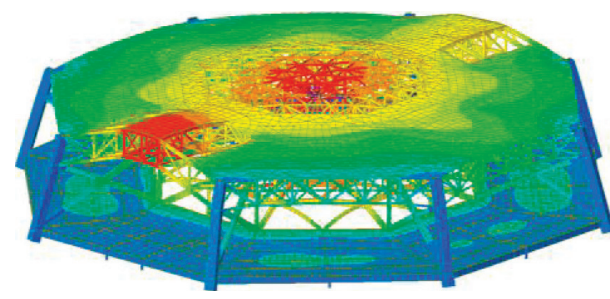

(a)

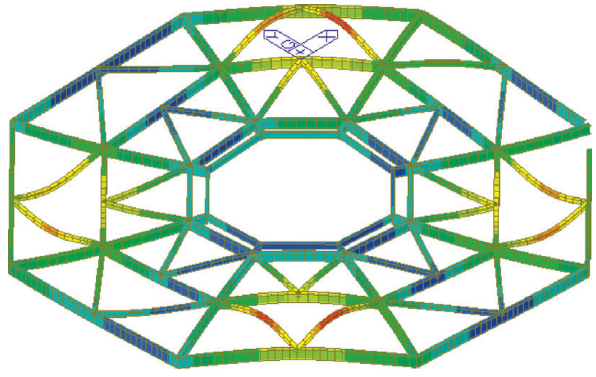

(c)

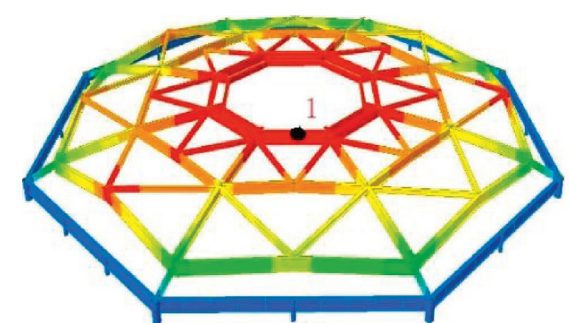

(b)

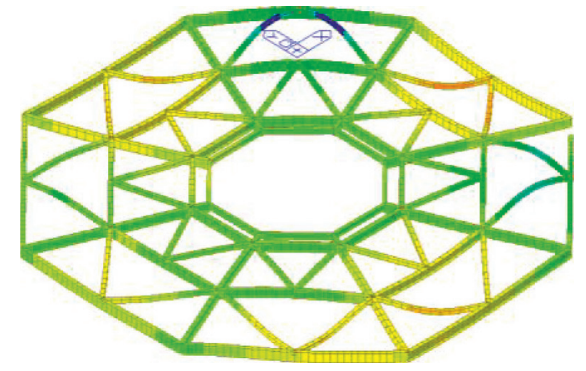

(d)

Figure 3: Vertical vibration mode shapes of the structure predicted with the global simplified FE model. (a) Mode shape of the global simplified FE model with $f 1=6.00 \mathrm{~Hz}$. (b) Mode shape of steel space frame-glass composite floor with $f 1=6.00 \mathrm{~Hz}$. (c) Mode shape of steel space frame-glass composite floor with $f 2=12.46 \mathrm{~Hz}$. (d) Mode shape of steel space frame-glass composite floor with $f 3=14.23 \mathrm{~Hz}$.

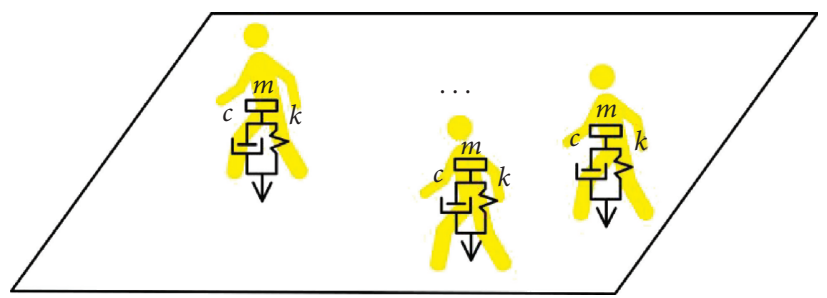

FIgURE 4: Schematic diagram of human-structure interaction.

TABLE 1: Human-induced vibration test description.

\begin{tabular}{|c|c|c|c|}
\hline Scenario & Walking condition & Walking frequency & Trajectory description \\
\hline$a$ & Single walking & $2.0 \mathrm{~Hz}$ & Following " 8 " line in one direction \\
\hline$b$ & Pair walking & Randomly normal walking & Following " 8 " line in opposite direction \\
\hline$c^{*}$ & 24 people walking & Randomly normal walking & $\begin{array}{c}\text { Following "S" line from the edge to the cave } \\
\text { Following clockwise direction. }\end{array}$ \\
\hline$d^{*}$ & 56 people walking & Randomly normal walking & $\begin{array}{l}24 \text { people in the inner closed ring } \\
32 \text { people in the outer closed ring }\end{array}$ \\
\hline
\end{tabular}

${ }^{*}$ According to the requirement of daily visitors during the normal opening period, the number of people was decided.

global simplified FE model $(f 1=6.00 \mathrm{~Hz})$ agrees well with the measured results $(6.09-6.12 \mathrm{~Hz})$. Moreover, it can be seen that with the number of people increasing, the first vertical modal frequency reduced.

4.2.2. Mode Shapes. The mode shapes of the floor were obtained by the peak picking of the average normalized power spectral densities (ANPSD) [38] in the frequency domain. Figure 8 demonstrates the first vertical mode shape of the floor and the ANPSD values on the measuring points. The maximum amplitudes of the first vibration mode of the floor presented at the edge of the central hole and gradually decreased from the center to the edge of the grid frame.

The modal assurance criterion (MAC) [32] is defined for the quantitative assessment of different vibration modes. The MAC value calculated with equation (1) is an important index to indicate the relevance of the different vibration mode shapes. Using the modal assurance criterion, the MAC value between the first vertical mode shape of the global FE model and the measured mode shape comes to $99.6 \%$. Both the first vertical frequency and the mode shape obtained by the global simplified FE model have a good agreement with 


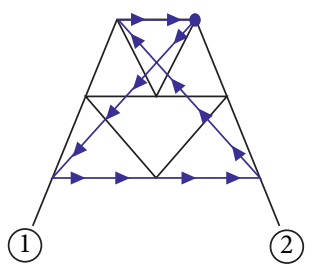

(a)

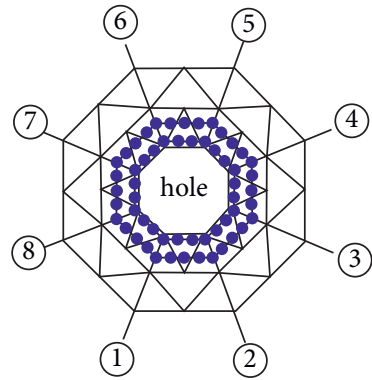

(d)

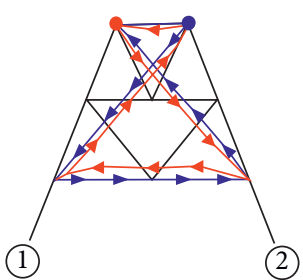

(b)

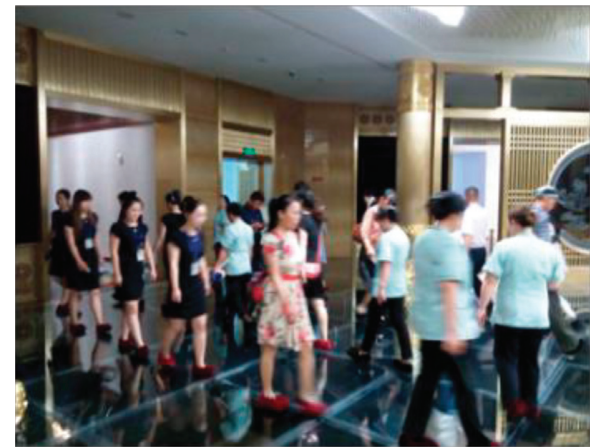

(e)

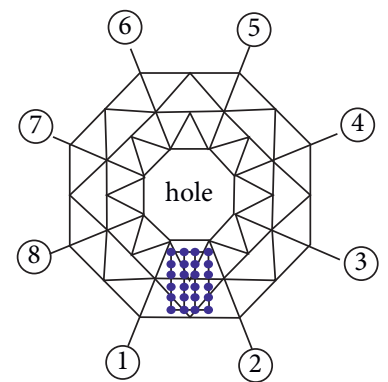

(c)

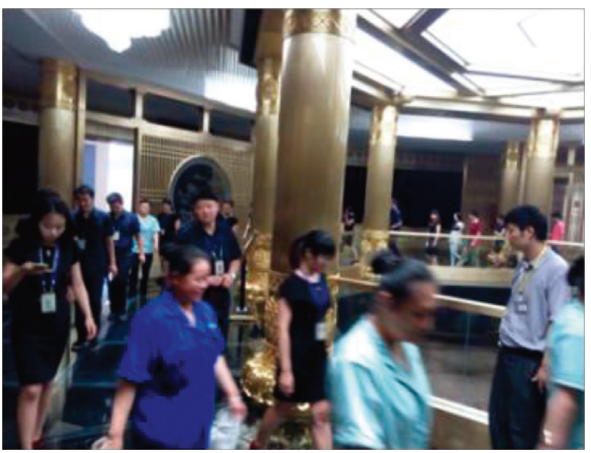

(f)

Figure 5: Trajectory of walking people. (a) Single walking. (b) Pair walking. (c) 24 people walking. (d) 56 people walking. (e) 24 people walking experiment. (f) 56 people walking experiment.

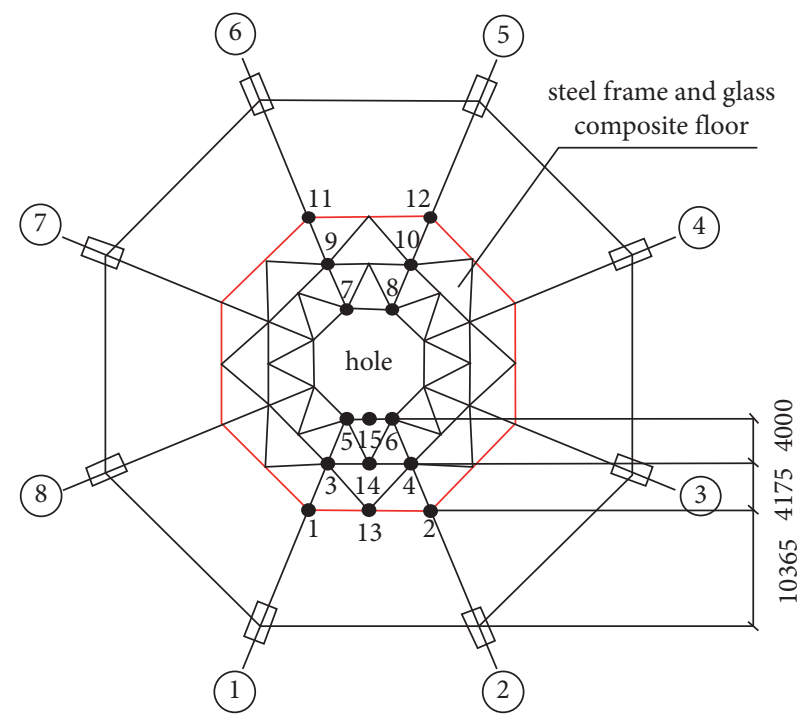

FIGURE 6: Layout of measuring points of the floor (mm).

those identified by experiments. It can be seen that the global simplified FE model can predict the first vertical vibration mode.

$$
\operatorname{MAC}_{i}=\frac{\left(\Phi_{a i}^{\mathrm{T}} \Phi_{e i}\right)^{2}}{\left(\Phi_{a i}^{\mathrm{T}} \Phi_{e i}\right)\left(\Phi_{e i}^{\mathrm{T}} \Phi_{e i}\right)},
$$

where $\Phi_{e i}$ is the $i$ th experimental mode shape and $\Phi_{a i}$ is the $i$ th analytical mode shape.
MAC value varies between 0 and 1 , where 0 indicates no similarity and 1 shows that the mode shapes are exactly the same.

4.2.3. Modal Damping Ratios. As shown in Table 2, the first vertical modal damping ratio of the floor identified by the self-spectrum FFT semi-power bandwidth method was $2.36 \%$. Table 3 reveals the effect of the number and walking features of pedestrians on the structural damping ratio. 

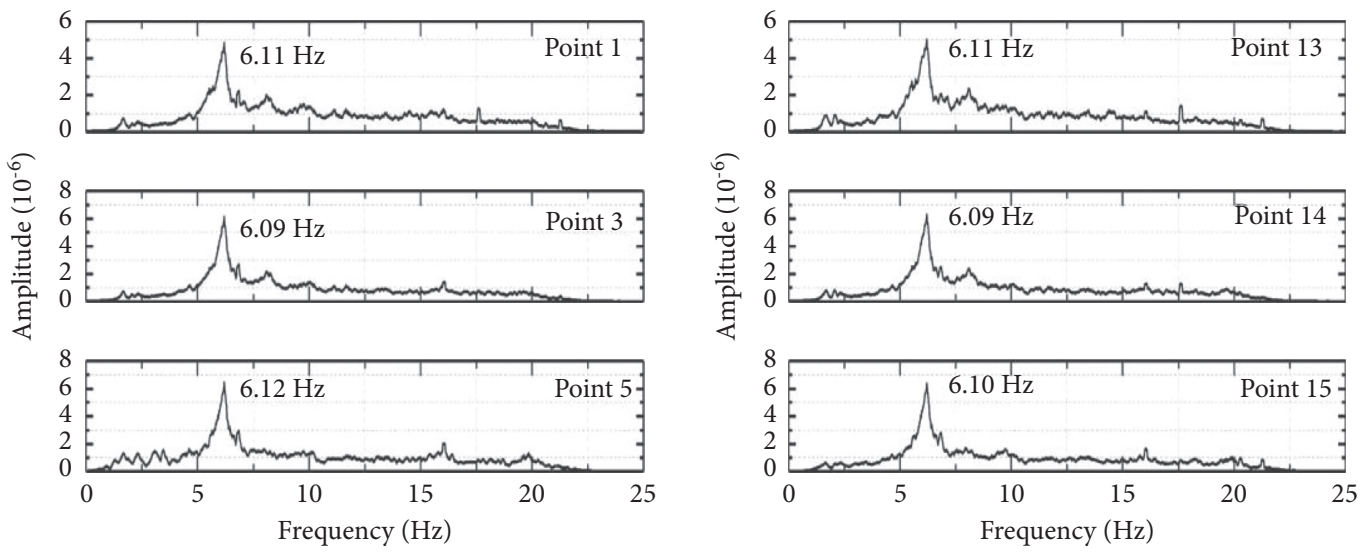

(a)
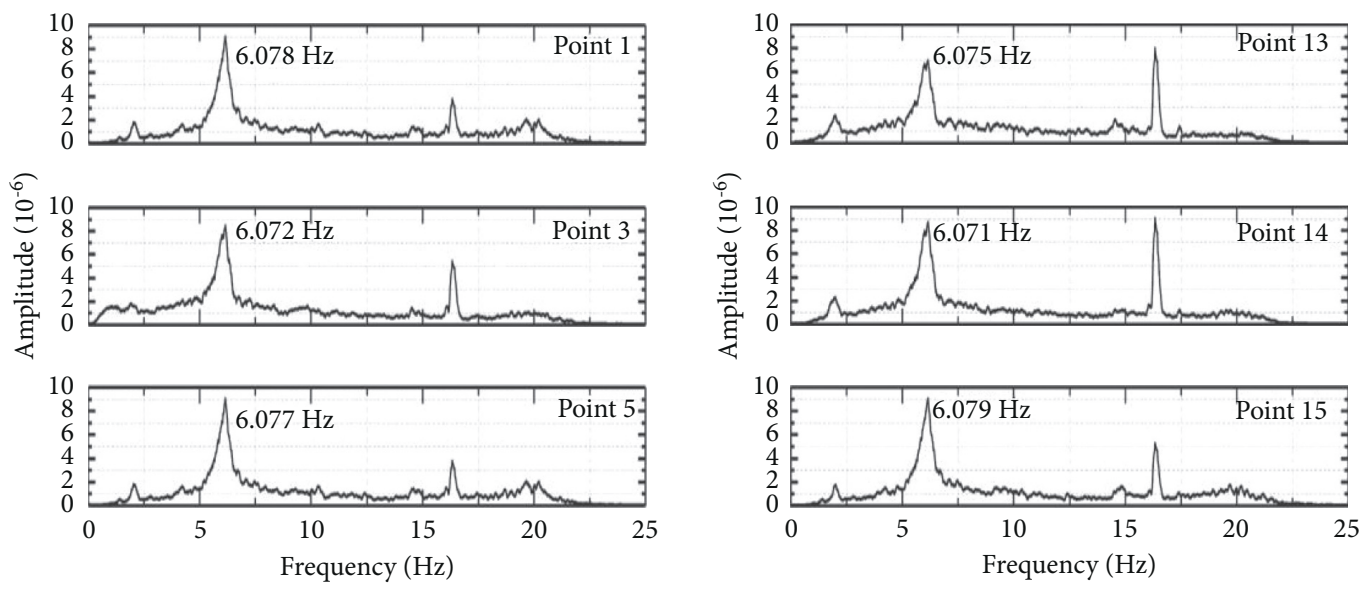

(b)
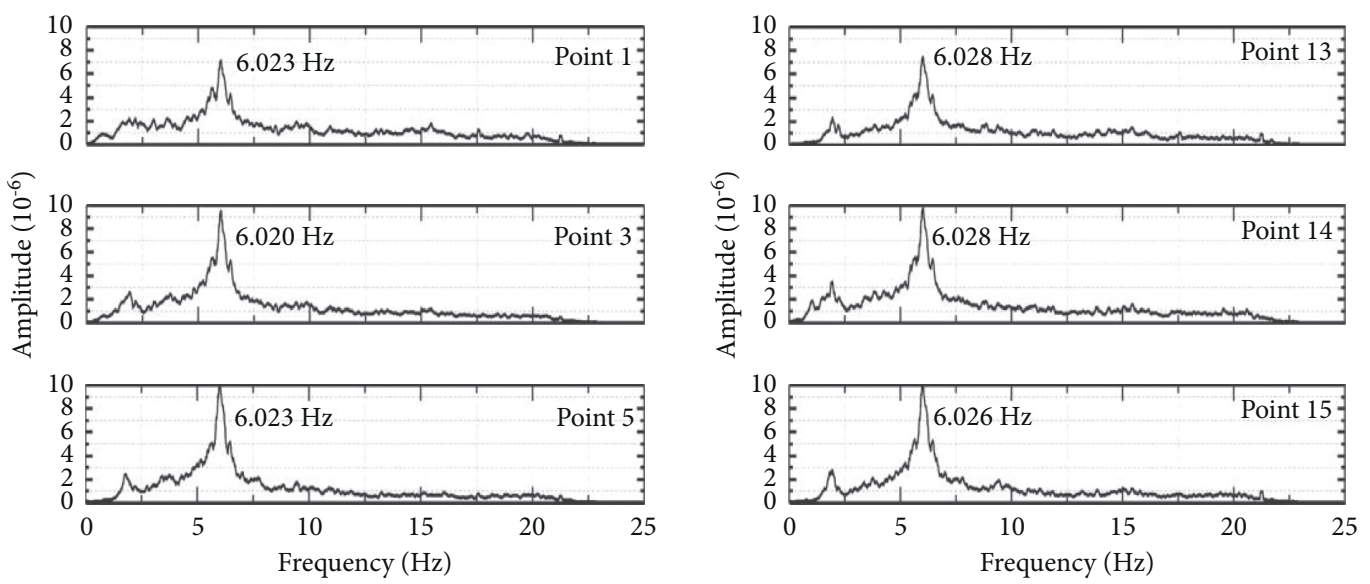

(c)

Figure 7: The amplitude-frequency curves of different measuring points. (a) Ambient excitation on the floor. (b) Ambient excitation on the part floor with 24 people. (c) Ambient excitation on the whole floor with 56 people.

Damping ratio is expected to vary with the number of pedestrians and their walking features. When the mass ratio between humans and structure was small, the humanstructure interaction effect can be negligible $[39,40]$. Hence, modal damping ratios of $2.36 \%$ can be chosen as the dynamic parameter of the FE model for simulation.
4.3. Human-Induced Vibration Results. Human-induced vibration tests were conducted to evaluate the vibration serviceability of the floor under various walking conditions. In reality, the human-induced vibration response is complex and unforeseen [41-43]. For the vibration serviceability assessment, considering the randomness of human activities, 
TABLE 2: Measured vertical frequencies and damping ratios of the floor.

\begin{tabular}{lcccc}
\hline \multirow{2}{*}{ Mode order } & Description & \multicolumn{2}{c}{ Frequency $(\mathrm{Hz})$} & Average \\
& & FFT & Damping ratio (\%) \\
\hline \multirow{3}{*}{ First order } & Ambient excitation & $6.09-6.12$ & 6.100 & 2.360 \\
& 24 people & $6.071-6.079$ & 6.075 & 2.545 \\
& 56 people & $6.02-6.028$ & 6.025 & 2.548 \\
\hline
\end{tabular}

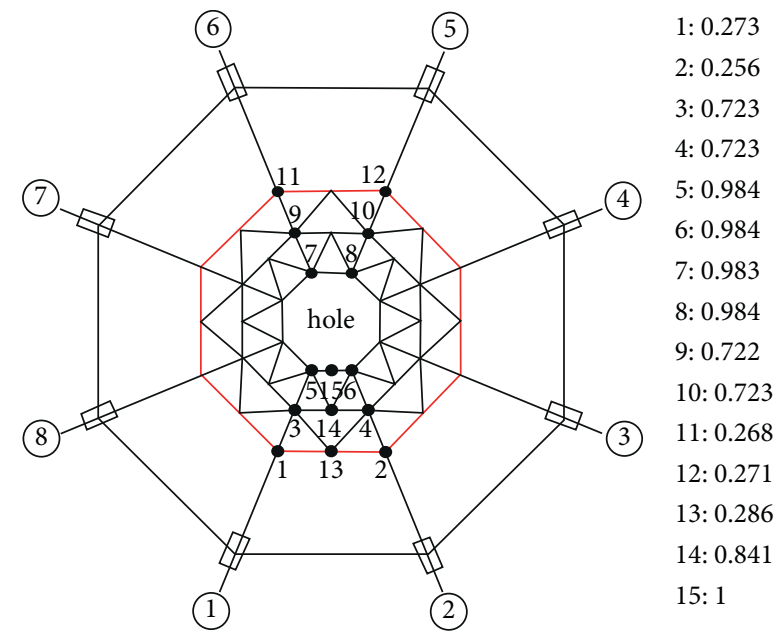

FIGURE 8: Measured FFT of the first vertical mode shape of the floor with ANPSD values.

TABLE 3: The effect of walking feature on the structural dynamic characteristics.

\begin{tabular}{lccc}
\hline Number & Feature & Damping ratio (\%) & Variation (\%) \\
\hline 24 & Following "S" line from the edge to the cave & 2.545 & 7.80 \\
56 & 24 people in the inner closed ring & 2.548 & 7.97 \\
\hline
\end{tabular}

the RMS acceleration responses [44] can be conducted as an index.

4.3.1. Experimental Results. Figure 9 plots the acceleration time-history curve of measuring point 15 under various working conditions. The value of maximum 10s RMS acceleration (10s-RMS) ( $T=10 \mathrm{~s})$ obtained from the timehistory curve under four scenarios achieves $18.6 \mathrm{~mm} \cdot \mathrm{s}^{-2}$, $13.9 \mathrm{~mm} \cdot \mathrm{s}^{-2}, \quad 5.0 \mathrm{~mm} \cdot \mathrm{s}^{-2}$, and $7.6 \mathrm{~mm} \cdot \mathrm{s}^{-2}$, respectively. When many people walk randomly, both the step frequency and phase angle of each person may be different, and thus the vertical excitation on the floor cannot produce a synergistic amplification effect. According to ISO criteria, the measured 10s-RMS acceleration responses to four scenarios were all below the ISO threshold value [20].

4.3.2. Numerical Results. Human's walking load can be regarded as a periodic excitation and the equivalent walking force expression can be set as Fourier series in equation (2) [45]. The dynamic load factors (DLFs) adopted by design guidelines in various countries or international organizations have slight differences, such as IABSE [46] with three harmonic components and AISC [47] with four-order harmonic components. For an extreme adverse prediction, the walking loading with the step frequency of $2.00 \mathrm{~Hz}$ was applied at the antinode of the significant mode shape. The time-history curve of the walking load model is shown in Figure 10, and responses under this load model are shown in Figure 11.

$$
F(t)=G\left[1+\sum_{i=1}^{n} a_{i} \sin \left(2 i \pi \bar{f}_{i} t-\varphi_{i}\right)\right],
$$

where $G$ is the static weight (taken as $750 \mathrm{~N}$ for real); $t$ is the time; $a_{i}$ is the dynamic load factor of $i$ th order; IABSE: $a_{1}=0.4, a_{2}=0.1$, and $a_{3}=0.1$; AISC: $a_{1}=0.5, a_{2}=0.2, a_{3}$ $=0.1$, and $a_{4}=0.05 ; \bar{f}_{i}$ is the frequency of $i$ th order load $\left(\bar{f}_{1}=1 / 3 \times 6.00 \mathrm{~Hz}=2.00 \mathrm{~Hz}\right)$; and $\varphi_{i}$ is the phase angle of $i$ th order load $\left(\varphi_{1}=0, \varphi_{2}=\pi / 2, \varphi_{3}=\pi / 2\right.$, and $\left.\varphi_{4}=\pi / 2\right)$.

The damping ratio of the model was temporarily set as $2.36 \%$ herein, and three loading situations with loading models were taken. The loading model was on the single layer (point 1 or point 2 plotted in Figure 2), and the other was taken on two layers (points 1 and 2) at the same time. The maximum calculated root-mean-square (RMS) acceleration is listed in Table 4. By the global simplified FE model, the maximum structural acceleration may not be obtained 


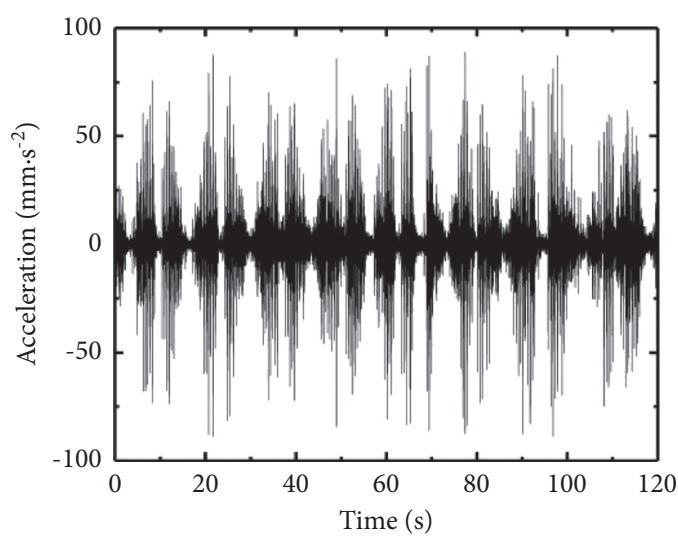

(a)

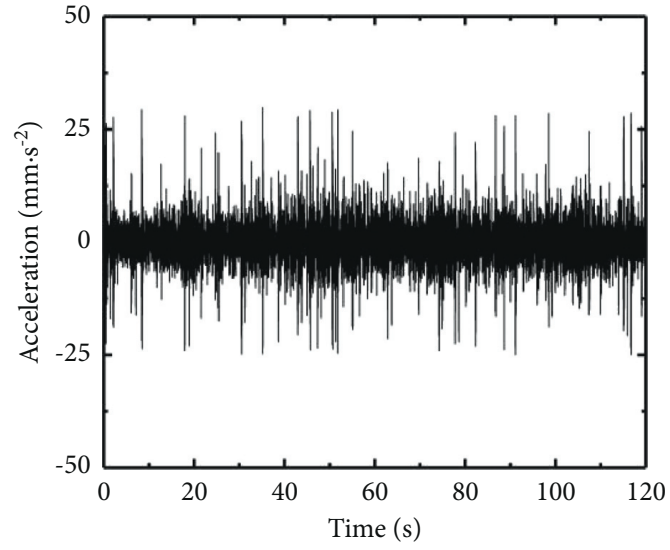

(c)

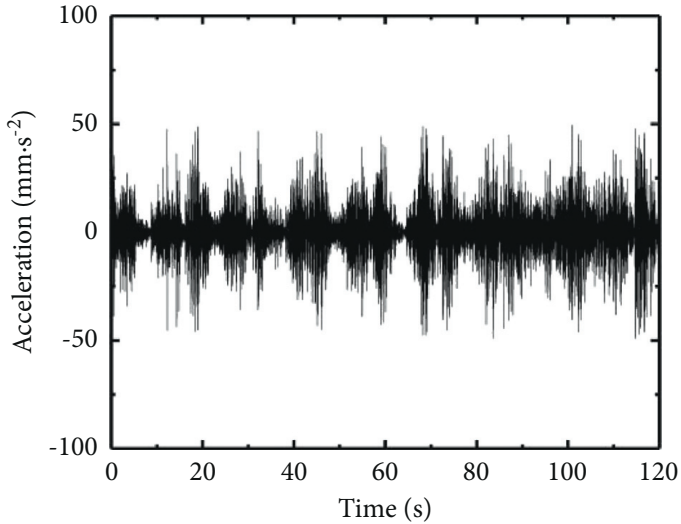

(b)

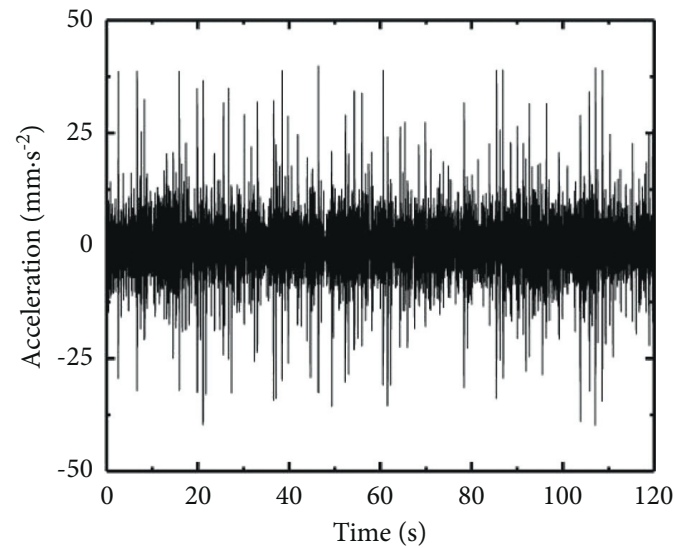

(d)

Figure 9: The time-history curves under different walking conditions. (a) Single walking. (b) Pair walking. (c) 24 people walking. (d) 56 people walking.

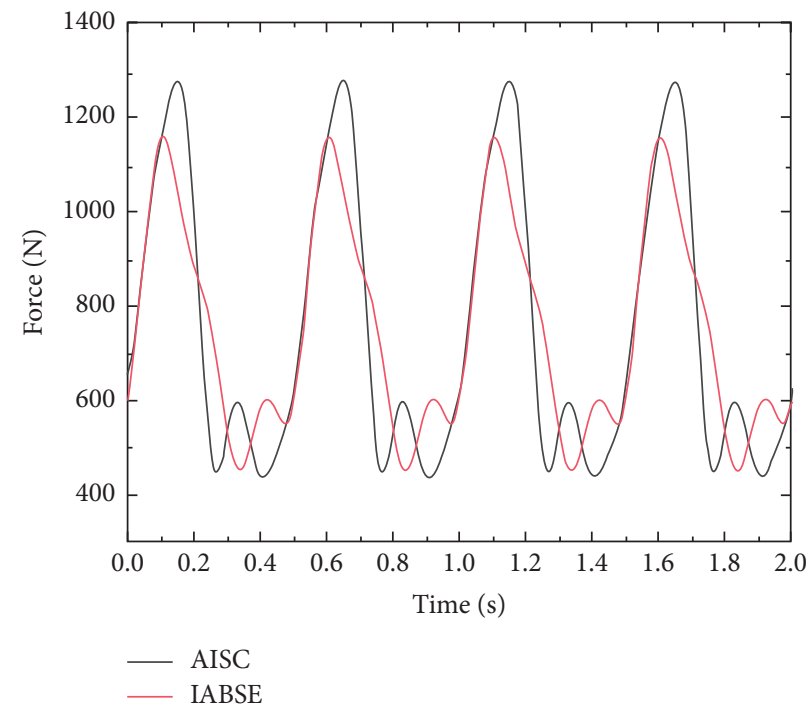

FIgURE 10: The time-history curve of walking load model. 


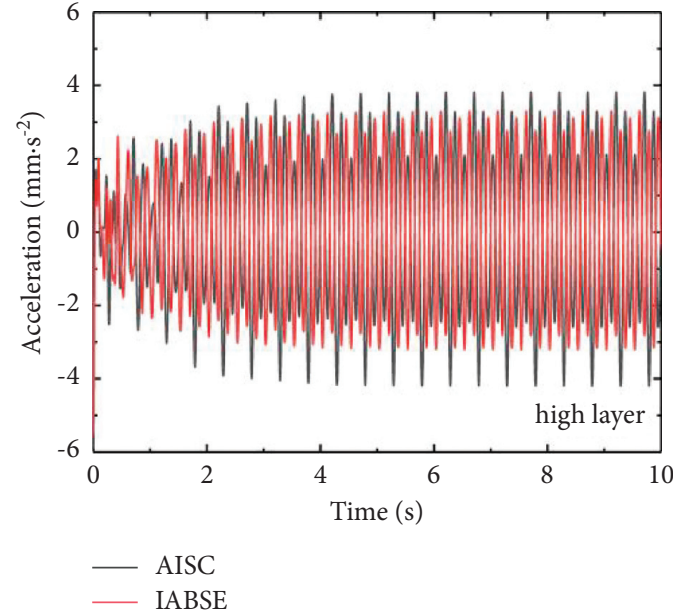

(a)

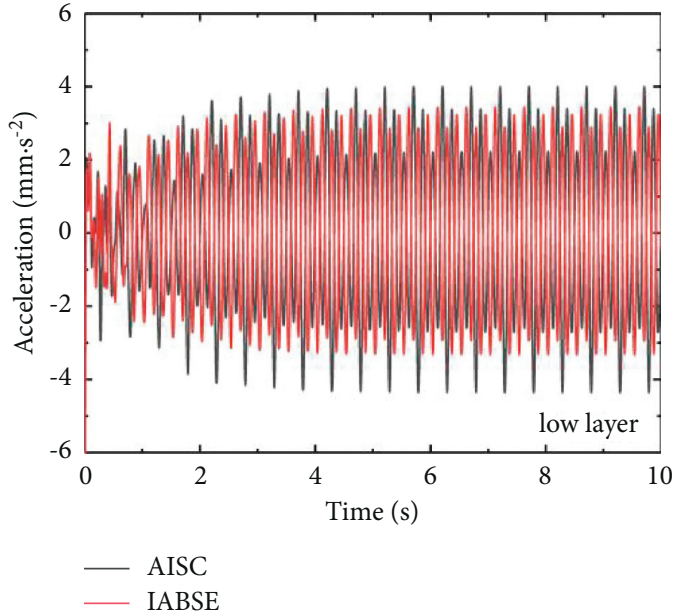

(b)

FIgURE 11: The acceleration response of global simplified FE model applied at point 1.

TABLE 4: Loading position and maximum RMS acceleration of the floor.

\begin{tabular}{|c|c|c|c|c|}
\hline \multirow{2}{*}{ Description } & \multirow{2}{*}{ Loading frequency $(\mathrm{Hz})$} & \multirow{2}{*}{ Loading position } & \multicolumn{2}{|c|}{ 10s-RMS acceleration $(\mathrm{mm} / \mathrm{s} 2)$} \\
\hline & & & Lower layer & High layer \\
\hline \multirow{4}{*}{ IABSE } & & Point 1 & 1.69 & 1.62 \\
\hline & 2.00 & Point 2 & 1.61 & 1.57 \\
\hline & & Points 1 and 2 & 3.30 & 3.19 \\
\hline & & Point 1 & 1.74 & 1.63 \\
\hline \multirow{2}{*}{ AISC } & 2.00 & Point 2 & 1.66 & 1.62 \\
\hline & & Points 1 and 2 & 3.40 & 3.27 \\
\hline
\end{tabular}

by loading on the single layer. According to the results of the two loading models, it can be inferred that the loading model in AISC can get bigger response.

4.3.3. Comparison of Experimental and Numerical Results. Compared with the measured results, the calculated RMS acceleration was underestimated, which can be explained by the effect of coupled phenomena between two layers. It was observed that the global simplified FE model of the structure failed to simulate the actual connection state. Although the dynamic characteristics of the global simplified FE model were in good agreement with the measured results, the global simplified FE model was incapable of evaluating the vibration serviceability of the floor. Hence, a new method of FE modeling will be presented for better prediction on the vibration serviceability of the SSSF-GCF in the next section.

\section{Equivalent Local FE Model of the Floor}

5.1. Establishment Method. Although the global simplified FE model has an advantage in presenting the structural characteristics, the simulated response is underestimated under human-induced vibration compared to the experiments. It is also found that the interstory coupled vibration is exaggerated by the global simplified FE model, which may be attributed to the effect of the connection simulation between different layers of the structure. To find how the coupled vibration between different layers in the SSSF-GCF worked on the simulated response, this section attempted to build an equivalent FE local model whose element units were the same as described in Section 3.1. The steps of the equivalent local model establishment are given in Figure 12.

5.1.1. Extraction. The single-layer FE model (SSSF-SCG) was the focus part of the entire structure extracted from the global simplified FE model.

5.1.2. Boundary Conditions. The six freedom degrees of the extractive part's peripheral node were constrained according to the real connection constraints of the extractive part (SSSF-SCG).

5.1.3. Node Redefinition. The twenty-four nodes which link the twenty-four hanging pillars were redefined as the elastic support. In elastic support, the stiffness in the direction of SDx, SDy, SRx, SRy, and SRz was defined as infinite and only the vertical stiffness $\mathrm{SDz}$ can be adjusted.

5.1.4. Adjustment parameters. When considering the principle of consistent frequency, the vertical stiffness of the elastic support was adjusted to $2460 \mathrm{kN} / \mathrm{m}$. This model was defined as an equivalent local FE model $A$ of which the first vertical frequency was the same as the global FE model. 


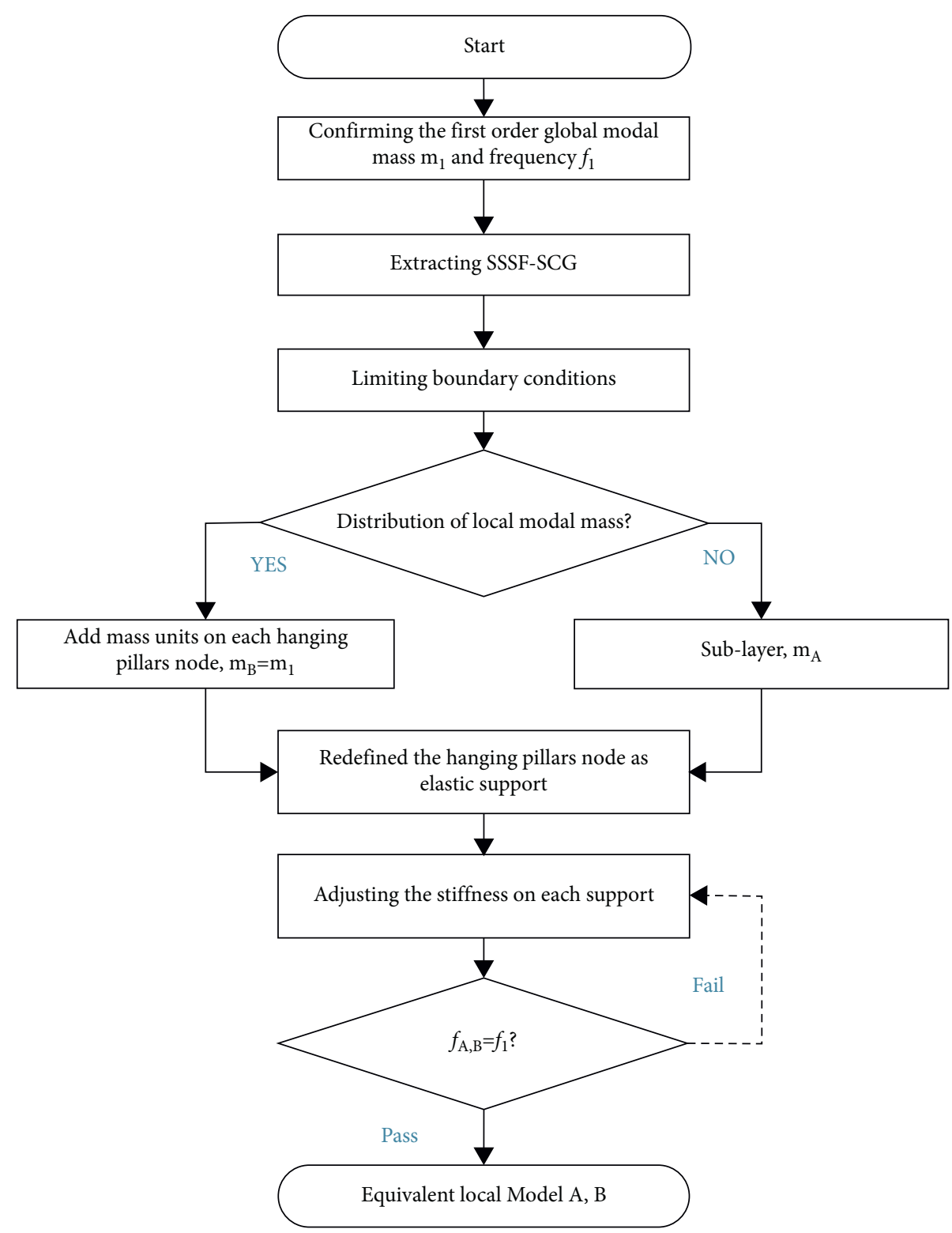

Figure 12: The flowchart of equivalent local model establishment.

When considering both the modal mass and the vertical frequency of the first mode, $57 \mathrm{~kg}$ mass units were added at each hanging pillar node, and the vertical stiffness of the elastic support was adjusted to $83500 \mathrm{kN} / \mathrm{m}$. In this way, an equivalent local FE model $B$ was defined.

\subsection{Dynamic Characteristic Evaluation of the Equivalent} Local Model. The first simulated vertical mode shape of the equivalent local model is illustrated in Figure 13. The MAC value between the equivalent local model $A$ (equivalent local model $B$ ) and the measured one is $99.3 \%$ (99.2\%). The MAC value between the equivalent local model $A$ (equivalent local model $B$ ) and the global finite element model is $98.3 \%$ $(98.2 \%)$, respectively. These MAC values indicated that the first vertical mode shape of the equivalent local FE model was similar to the measured results. It also can be seen that the equivalent local FE model $A$ had a better agreement than the equivalent local FE model $B$ when compared with the measured first vertical mode shape.

5.3. Human-Induced Vibration Response Evaluation of the Equivalent Local FE Model. The walking loading model within AISC was applied at point 3 (in Figure 13), and the $10 \mathrm{~s}-\mathrm{RMS}$ acceleration value achieves $18.0 \mathrm{~mm} / \mathrm{s}^{2}$ by the equivalent local FE model $A$ while it achieves $2.3 \mathrm{~mm} / \mathrm{s}^{2}$ by the equivalent local FE model $B$. The comparison between the simulated results by different models is demonstrated in Figure 14. The simulated value of the equivalent local model $B$ has a large difference compared with the measured value. The vertical RMS acceleration by the equivalent local model $A$ was the same as that of the field results. Therefore, the equivalent local FE model with a 


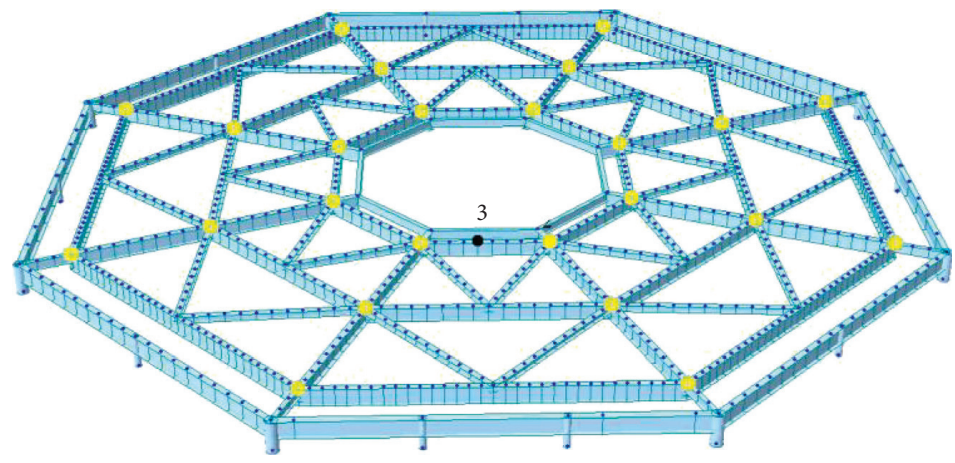

(a)

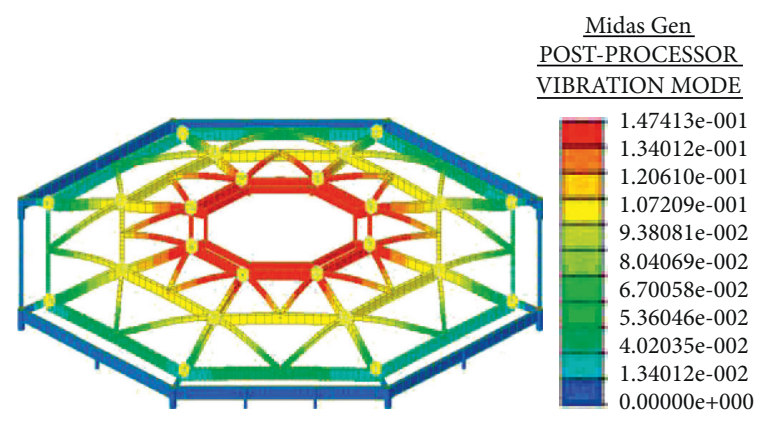

(b)

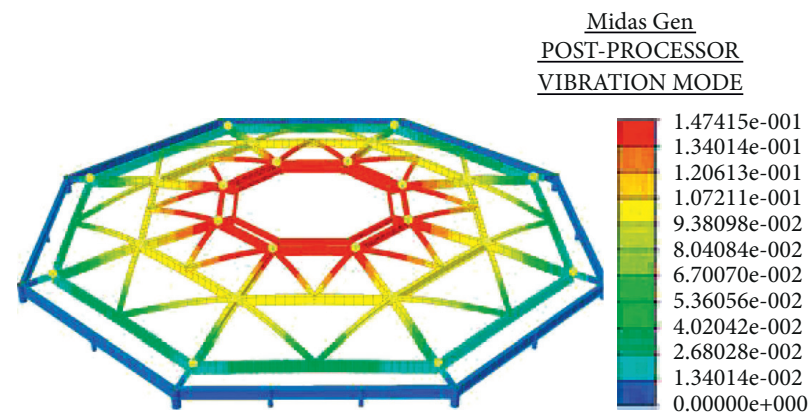

(c)

Figure 13: Simulated first vertical mode shape of the equivalent local FE model. (a) The equivalent local FE model of structure. (b) Equivalent local model $A$. (c) Equivalent local model $B$.

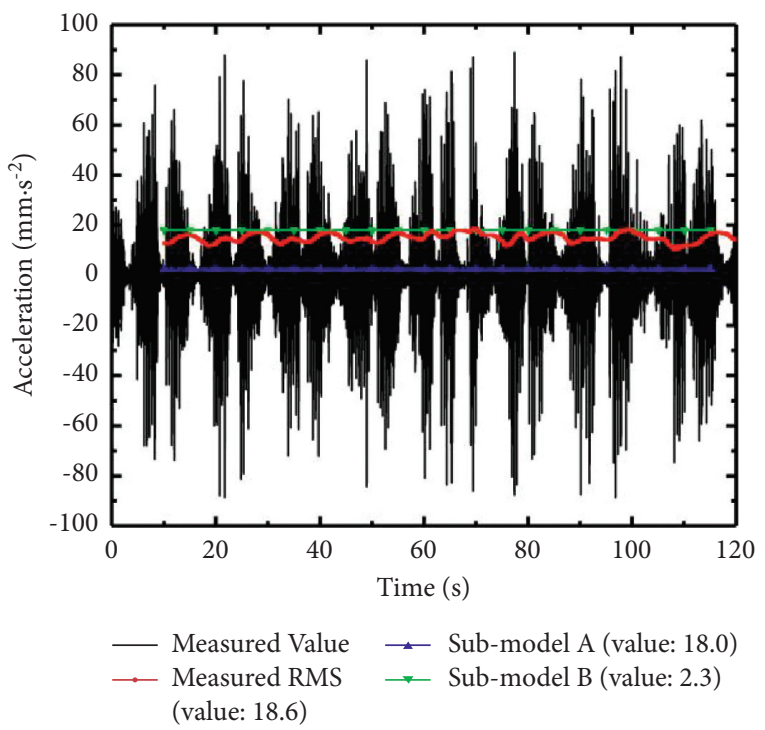

FIGURE 14: The time-history curve of condition and the RMS of the equivalent local model simulation.

modified stiffness of vertical hanging pillar was feasible to evaluate the vibration serviceability of the suspended composite floor.

It also can be indicated that the equivalent local model $A$ can reflect the real level of the floor vibration serviceability. The equivalent local model $B$ was similar to the global simplified FE model, which revealed that the global simplified FE model may exaggerate the coupled effect of modal mass between different layers.

\section{The Effect of Damping Ratio on the Acceleration Response of the Floor}

Due to the existence of the rubber layer between the glass slab and the steel frame, the modal damping ratio of the SSSF-GCF was found to be a little higher than that of conventional steel composite floor structures (1.0\%-2.0\%) [48]. Previous studies [49-51] have demonstrated that the damping ratio had a great influence on the vibration 


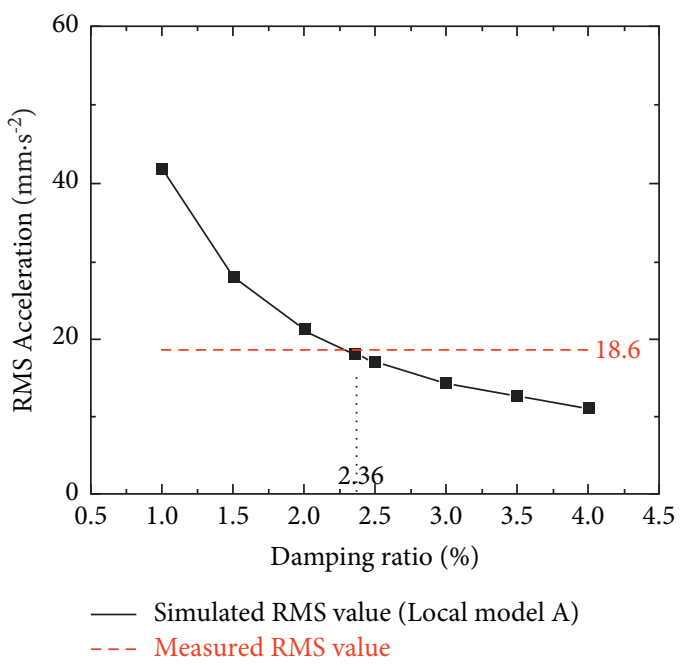

FIGURE 15: The effect of structural damping ratio on the vertical maximum RMS acceleration of the floor.

response of the floor. Within the equivalent local FE model $\mathrm{A}$, the effect of the damping ratio on the acceleration response of the SSSF-GCF was investigated. As shown in Figure 15, the RMS acceleration decreased significantly with the increase of the structural damping ratio.

\section{Conclusions}

As a new type of floor system, the suspended steel space frame-glass composite floor (SSSF-GCF) presented in this paper can well satisfy the requirements of large-span space. The vertical dynamic characteristics of SSSF-GCF were obtained by the field test. Due to the existence of the rubber layer between the glass slab and the steel frame, the first vertical damping ratio of the SSSF-GCF can be found to be a little higher than that of conventional steel composite floor structures. The viewing area for the visitors corresponds to the most sensitive vibration area in the first vertical mode shape of the SSSF-GCF, and the first vertical frequency is close to the harmonic of the walking frequency of pedestrians. According to field experimental results, the responses of the SSSF-GCF under all conditions are below the ISO threshold value. It can be concluded that the SSSF-GCF has good dynamic performances on vibration serviceability.

The global simplified FE model is presented to simulate the whole suspended structure. Although it is in good agreement with the first vertical frequency and the mode shape identified by experimental results, the vertical coupled vibration between different layers is exaggerated within the global simplified FE model, which causes the underestimated vertical human-induced acceleration response of the floor. Accordingly, an equivalent local FE model of the SSSF-GCF is proposed and updated via adjusting the vertical stiffness of the hanging pillars. Comparative results show that the equivalent local FE model can well predict both the dynamic characteristics and human-induced vibration response of the floor. Hence, the equivalent local model establishing method proposed in this paper can provide a reference for the vertical vibration serviceability assessment of the suspended floor system.

\section{Data Availability}

The data used to support the findings of this study are included within the article.

\section{Conflicts of Interest}

The authors declare that there are no conflicts of interest regarding the publication of this paper.

\section{Acknowledgments}

The authors gratefully acknowledge the financial support from the National Key Research and Development Program of China (grant no. 2017YFC0703900).

\section{References}

[1] A. A. Chiniforush, M. Makki Alamdari, U. Dackermann, H. R. Valipour, and A. Akbarnezhad, "Vibration behaviour of steel-timber composite floors, part (1): experimental \& numerical investigation," Journal of Constructional Steel Research, vol. 161, pp. 244-257, 2019.

[2] A. Hassanieh, A. A. Chiniforush, H. R. Valipour, and M. A. Bradford, "Vibration behaviour of steel-timber composite floors, part (2): evaluation of human-induced vibrations," Journal of Constructional Steel Research, vol. 158, pp. 156-170, 2019.

[3] J. G. S. da Silva, S. A. L. de Andrade, and E. D. C. Lopes, "Parametric modelling of the dynamic behaviour of a steelconcrete composite floor," Engineering Structures, vol. 75, pp. 327-339, 2014.

[4] A. V. A. Mello, J. G. S. da Silva, P. C. G. d. S. Vellasco, S. A. L. de Andrade, and L. R. O. de Lima, "Dynamic analysis of composite systems made of concrete slabs and steel beams," Journal of Constructional Steel Research, vol. 64, no. 10, pp. 1142-1151, 2008. 
[5] C. A. O. Ferrante, S. A. L. de Andrade, L. R. O. de Lima, and P. C. G. S. Vellasco, "Analytical study and experimental tests on innovative steel-concrete composite floorings," Journal of Constructional Steel Research, vol. 168, Article ID 10586, 2019.

[6] S. Sandun De Silva and D. P. Thambiratnam, "Dynamic characteristics of steel-deck composite floors under humaninduced loads," Computers \& Structures, vol. 87, no. 17-18, pp. 1067-1076, 2009.

[7] L. F. Costa-Neves, J. G. S. da Silva, L. R. O. de Lima, and S. Jordão, "Multi-storey, multi-bay buildings with composite steel-deck floors under human-induced loads: the human comfort issue," Computers \& Structures, vol. 136, pp. 34-46, 2014.

[8] S. Zhang and L. Xu, "Determination of equivalent rigidities of cold-formed steel floor systems for vibration analysis, Part I: Theory," Thin-Walled Structures, vol. 132, pp. 25-35, 2018.

[9] L. Xu, S. Zhang, and C. Yu, "Determination of equivalent rigidities of cold-formed steel floor systems for vibration analysis, Part II: evaluation of the fundamental frequency," Thin-Walled Structures, vol. 132, pp. 1-15, 2018.

[10] W. D. Varela and R. C. Battista, "Control of vibrations induced by people walking on large span composite floor decks," Engineering Structures, vol. 33, no. 9, pp. 2485-2494, 2011.

[11] C. M. Abeysinghe, D. P. Thambiratnam, and N. J. Perera, "Dynamic performance characteristics of an innovative hybrid composite floor plate system under human-induced loads," Composite Structures, vol. 96, pp. 590-600, 2013.

[12] C. M. Abeysinghe, D. P. Thambiratnam, and N. J. Perera, "Flexural performance of an innovative hybrid composite floor plate system comprising glass-fibre reinforced cement, polyurethane and steel laminate," Composite Structures, vol. 95, pp. 179-190, 2013.

[13] K. Lee, S.-H. Lee, G.-C. Kim, and S.-S. Woo, "Global vertical resonance phenomenon between steel building and human rhythmic excitations," Journal of Constructional Steel Research, vol. 92, pp. 164-174, 2014.

[14] I. M. Ahmed and K. D. Tsavdaridis, "The evolution of composite flooring systems: applications, testing, modelling and eurocode design approaches," Journal of Constructional Steel Research, vol. 155, pp. 286-300, 2019.

[15] J. Kralik and J. Kralik Jr, "Experimental and sensitivity analysis of the vibration impact to the human comfort," Procedia Engineering, vol. 190, pp. 480-487, 2017.

[16] L. Cao, H. T. Qi, and J. Li, "Experimental and numerical studies on the vibration serviceability of fanshaped prestressed concrete floor," International Journal of Distributed Sensor Networks, vol. 14, no. 8, 2018.

[17] M. M. Ebadi, G. Doudak, and I. Smith, "Finite-element modeling and parametric study of glulam beam-and-deck floors," Journal of Structural Engineering, vol. 143, no. 9, Article ID 04017106, 2017.

[18] N. Labonnote, A. Rønnquist, and K. A. Malo, "Prediction of material damping in timber floors, and subsequent evaluation of structural damping," Materials and Structures, vol. 48, no. 6, pp. 1965-1975, 2015.

[19] N. C. Van Engelen and J. Graham, "Comparison of prediction and measurement techniques for pedestrian-induced vibrations of a low-frequency floor," Structural Control and Health Monitoring, vol. 26, 2019.

[20] Q. An, Z. Chen, Q. Ren, H. Liu, and X. Yan, "Control of human-induced vibration of an innovative CSBS-CSCFS," Journal of Constructional Steel Research, vol. 115, pp. 359-371, 2015.
[21] C. Bedon, "Experimental investigation on vibration sensitivity of an indoor glass footbridge to walking conditions," Journal of Building Engineering, vol. 29, Article ID 101195, 2020.

[22] C. Bedon, M. Fasan, and C. Amadio, "Vibration analysis and dynamic characterization of structural glass elements with different restrains based on operational modal analysis," Buildings, vol. 9, no. 13, pp. 1-23, 2019.

[23] S. J. Bennison, G. Technical, M. F. Serruys et al., "Designing the grand canyon's new laminated glass walkway," Glass Performance Days in Finland, pp. 333-335, 2007.

[24] T. B. Wan, "Key techniques of design of special shape glass floor suspension bridge over Zhangjiajie Grand Canyon (in Chinese)," China Bridge Construction, vol. 47, no. 1, pp. 6-11, 2017.

[25] C. Bedon and M. Fasan, "Reliability of field experiments, analytical methods and pedestrian's perception scales for the vibration serviceability assessment of an in-service glass walkway," Applied Sciences, vol. 9, no. 9, p. 1936, 2019.

[26] Q. Feng, L. Fan, L. Huo, and G. Song, "Vibration reduction of an existing glass window through a viscoelastic material-based retrofit," Applied Sciences, vol. 8, no. 7, p. 1061, 2018.

[27] C. Bedon, "Diagnostic analysis and dynamic identification of a glass suspension footbridge via on-site vibration experiments and FE numerical modelling," Composite Structures, vol. 216, pp. 366-378, 2019.

[28] H. F. Lam, J. Hu, and M. O. Adeagbo, "Bayesian model updating of a 20-story office building utilizing operational modal analysis results," Advances in Structural Engineering, vol. 22, no. 16, pp. 3385-3394, 2019.

[29] M. Robertson, D. Holloway, and A. Taoum, "Vibration of suspended solid-timber slabs without intermediate support: assessment for human comfort," Australian Journal of Structural Engineering, vol. 19, pp. 1-13, 2018.

[30] T. Guo, Z. Cao, Z. Zhang, and A. Li, "Frequency domainbased analysis of floor vibrations using the dynamic stiffness matrix method," Journal of Vibration and Control, vol. 25, no. 4, pp. 763-776, 2018.

[31] W. Ye, J. Liu, H. Fang, and G. Lin, "High-performance analysis of the interaction between plate and multi-layered elastic foundation using SBFEM-FEM," Composite Structures, vol. 214, pp. 1-11, 2019.

[32] J. S. Bai and W. X. Ren, "Structural finite element model updating using ambient vibration test results," Journal of Structural Engineering, vol. 131, pp. 617-628, 2005.

[33] Q. Zhu, K. Liu, and L. Liu, "Experimental and numerical analysis on serviceability of cantilevered floor based on human-structure interaction," Journal of Constructional Steel Research, vol. 173, Article ID 106184, 2020.

[34] L. Lu, Y. Lei, Y. Yu, F. Bu, and X. Wu, "Study on human comfort of suspended floor under large-span steel truss roof (in Chinese)," Build Structure, vol. 49, no. 19, pp. 51-56, 2019.

[35] A. S. Mohammed and A. Pavic, "Effect of walking people on dynamic properties of floors," Procedia Engineering, vol. 199, pp. 2856-2863, 2017.

[36] E. Shahabpoor, A. Pavic, V. Racic, and S. Zivanovic, "Effect of group walking traffic on dynamic properties of pedestrian structures," Journal of Sound and Vibration, vol. 387, pp. 207-225, 2017.

[37] E. Shahabpoor, A. Pavic, and V. Racic, "Interaction between walking humans and structures in vertical direction: a literature review," Shock and Vibration, vol. 2016, Article ID 3430285, 22 pages, 2016.

[38] W.-X. Ren, X.-L. Peng, and Y.-Q. Lin, "Experimental and analytical studies on dynamic characteristics of a large span 
cable-stayed bridge," Engineering Structures, vol. 27, no. 4, pp. 535-548, 2005.

[39] Q. K. Zhu, X. L. Hui, Y. F. Du, and Q. Zhang, "A full path assessment approach for vibration serviceability and vibration control of footbridges," Structural Engineering \& Mechanics, vol. 70, pp. 768-779, 2019.

[40] L. Klaus, L. Geert, V. N. Katrien, D. R. Guido, and V. D. B. Peter, "Robust vibration serviceability assessment of footbridges subjected to pedestrian excitation: strategy and applications," Engineering Structures, vol. 171, pp. 236-246, 2018.

[41] C. C. Caprani and E. Ahmadi, "Formulation of humanstructure interaction system models for vertical vibration," Journal of Sound and Vibration, vol. 377, pp. 346-367, 2016.

[42] K. Van Nimmen, G. Lombaert, G. De Roeck, and P. Van den Broeck, "The impact of vertical human-structure interaction on the response of footbridges to pedestrian excitation," Journal of Sound and Vibration, vol. 402, pp. 104$121,2017$.

[43] J. M. W. Brownjohn, P. Fok, and M. Roche, "Long-span steel pedestrian bridge at Singapore Changi Airport-part1: prediction of vibration serviceability problems," Structural Engineer, vol. 82, no. 16, pp. 21-27, 2004.

[44] J. Chen, Z. Han, and R. Xu, "Effects of human-induced load models on tuned mass damper in reducing floor vibration," Advances in Structural Engineering, vol. 22, no. 11, pp. 2449-2463, 2019.

[45] D. E Allen and T. M. Murray, "Design criterion for vibrations due to walking," Engineering Journal: American Institute of Steel Construction, vol. 30, no. 4, pp. 117-129, 1993.

[46] Y. Matsumoto, T. Nishioka, and H. Shiojiri, "Dynamic design of footbridges," IABSE Proceedings, pp. 17-78, 1978.

[47] T. M. Murray, D. E. Allen, and E. E Ungar, "Floor vibrations due to human activity," Steel Design Guide, vol. 11, 1997.

[48] C. Díaz, P. Martí, M. Victoria, and O. M. Querin, "Review on the modelling of joint behaviour in steel frames," Journal of Constructional Steel Research, vol. 67, no. 5, pp. 741-758, 2011.

[49] C. J. Middleton and J. M. W. Brownjohn, "Response of high frequency floors: a literature review," Engineering Structures, vol. 32, no. 2, pp. 337-352, 2010.

[50] A. P. Jeary, "Damping in tall buildings-A mechanism and A predictor," Earthquake Engineering \& Structural Dynamics, vol. 14, no. 5, pp. 733-750, 1986.

[51] M. Willford, P. Young, and C. Field, "Predicting footfallinduced vibration: Part 1," Proceedings of the Institution of Civil Engineers - Structures and Buildings, vol. 160, no. 2, pp. 65-72, 2007. 